\title{
OBITUARY OF \\ PROFESSOR ETIENNE DE VYLDER (1937-2004)
}

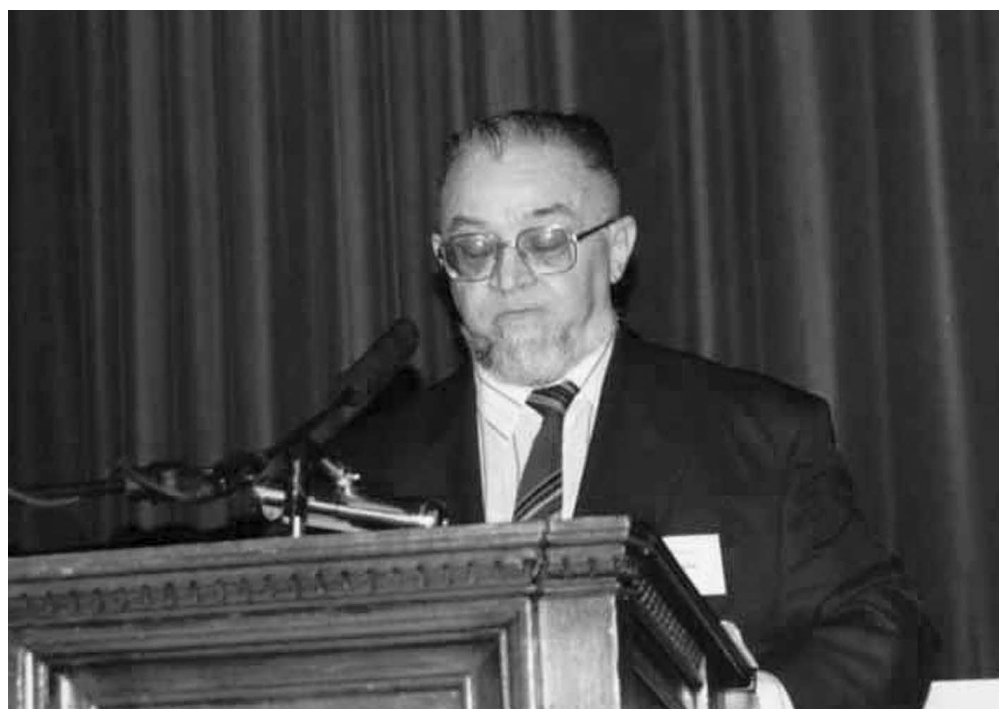

Professor Etienne De Vylder in 1998

Professor Etienne De Vylder passed away in February 2004.

Professor De Vylder was among those who played an important role in the considerable development of actuarial science since the beginning of the 1970's. He did his graduate studies at the Université Catholique de Louvain (Louvainla-Neuve, Belgium) and obtained his Ph.D. in 1966. His thesis was on generalized Poisson processes. He spent most of his academic career at this same university.

Professor De Vylder was an outstanding and passionate researcher with brilliant and creative ideas. He showed profoundness and rigour in his scientific work throughout his career. His enthusiasm for finding answers to problems or creating new ones went as far as always carrying a small notebook in his pocket just in case a good idea came along.

His contribution to various fields of actuarial science is enormous, most notably in modern risk theory, ruin theory, credibility theory, optimization theory, ordering of risks, and life insurance. Anyone working on problems in ruin theory is familiar with the so-called De Vylder approximation of the ruin probability, but there is also De Vylder's credibility model for IBNR, as well as De Vylder's least squares model for IBNR. He was the author or co-author 
of several textbooks in actuarial science, such as Advanced Risk Theory - A selfcontained introduction, Life Insurance Theory (Actuarial Perspectives), and Insurance Premiums. He was one of the founding editors of Insurance: Mathematics and Economics.

Professor De Vylder was known for his deep understanding of complex concepts and his ability to explain them in simple terms. Having been his Ph.D. students, we can assert how dedicated he was to the graduate students studying under his supervision. He would always make time to meet with us on a regular basis to follow the progress of our work. His interest in the advancement of our research went as far as asking one of us to call him at any hour of the night if the desired result of a simulation problem was obtained. We cannot recall these weekly meetings without mentioning the kindness of Professor De Vylder; he would never come to them without chocolates or pastries to share.

His generosity and willingness to help young researchers greatly supported them in their work. While reviewing a paper or during a talk, he would focus on the positive aspects of the research project, most often making suggestions to improve or advance the work begun. As a member of a Ph.D. committee, he provided new insights to young researchers to pursue their research and explore new avenues.

Professor De Vylder was someone who lived life to its fullest. People who knew him surely remember agreeable moments shared with him. They were always filled with laughter and surprise.

Etienne, we sincerely thank you for your kindness and support and for all the enjoyable times we have spent in your company. You have shown us that research must be done with perseverance and a smile. 